\title{
Flow mediated dilation and carotid intima media thickness in patients with chronic gastritis associated with Helicobacter pylori infection
}

\author{
Arezo JUDAKI ${ }^{1}$, Siros NOROZI ${ }^{2}$, Mohammad Reza Hafezi AHMADI ${ }^{3}$,Samira Mis GHAVAM², \\ Khairollah ASADOLLAHI ${ }^{4}$ and Asghar RAHMANI ${ }^{5}$
}

Received 9/4/2017 Accepted 17/7/2017

\begin{abstract}
Background - Endothelial dysfunction is one of the early stages of vascular diseases. Objective - The aim of this study was to investigate the endothelial dysfunction markers in patients with chronic gastritis associated with Helicobacter pylori (H. pylori) infection. Methods - By a cross sectional study, basic and clinical information of 120 participants (40 patients with positive $H$. pylori infection, 40 patients with negative $H$. pylori infection and 40 healthy people) were analyzed. Carotid intima media thickness and flow-mediated dilation levels were measured in all patients and controls. Soluble vascular cell adhesion molecule-1 (sVCAM-1) and intercellular adhesion molecule-1 (ICAM-1) were measured with Elisa for all subjects. IgG level was assessed in chronic gastritis patients. Results - The flow-mediated dilation level in patients with positive $H$. pylori infection $(0.17 \% \pm 0.09)$ was significantly lower than those with negative $H$. pylori infection $(0.21 \% \pm 0.10, P<0.05)$ and compared to the control group $(0.27 \%$ $\pm 0.11, P<0.05)$. Carotid intima media thickness level in patients with positive $H$. pylori infection $(0.58 \pm 0.13 \mathrm{~mm})$ was significantly higher than those with negative $H$. pylori infection $(0.48 \pm 0.32 \mathrm{~mm}, P<0.05)$ and compared to the control group $(0.36 \pm 0.44 \mathrm{~mm}, P<0.05)$. The mean level of sICAM-1 in positive $H$. pylori infection group $(352.16 \pm 7.54 \mathrm{pg} / \mathrm{mL})$ was higher than negative $H$. pylori infection group $(332.64 \pm 8.75 \mathrm{pg} / \mathrm{mL}=0.75)$ and compared to the control group $(236.32 \pm 12.43 \mathrm{pg} / \mathrm{mL}, P<0.05)$. A direct relationship was revealed between flow-mediated dilation and carotid intima media thickness changes and between sICAM-1 and sVCAM-1 associated with the level of H. pylori IgG in chronic gastritis. Conclusion - The levels of flow-mediated dilation, carotid intima media thickness and sICAM-1 were higher among patients with positive $H$. pylori infection. Patients with chronic gastritis associated with $H$. pylori infection are at risk of endothelial dysfunction due to flow-mediated dilation and carotid intima media thickness abnormalities and increased level of sICAM-1 and sVCAM-1.
\end{abstract}

HEADINGS - Gastritis. Helicobacter pylori. Endothelial growth factors. Carotid intima-media thickness.

\section{INTRODUCTION}

Helicobacter pylori $(H$. pylori) is a gram-negative bacterium that causes one of the most common chronic infections in human. This microorganism is a known pathogen associated with chronic gastritis, peptic ulcer disease (PUD), gastric carcinoma and gastric lymphoma. However, the clinical effects of this pathogen is beyond of the stomach and the epidemiological studies suggested an association between $H$. pylori infection and atherosclerosis or vascular diseases. The role of $H$. pylori and its virulence factors involved in the pathogenesis of atherosclerosis has not been identified so $\mathrm{far}^{(18)}$. Atherosclerosis as a chronic inflammatory disease is a multifactorial inflammatory phenomenon and it is known that some pathogens is associated with chronic infection can induce inflammation $^{(12)}$. In the case of $H$. pylori infection, the organism after colonization, by activating proinflammatory signaling pathways such as nuclear factor kappa B $(\mathrm{NF}-\kappa \mathrm{B})^{(8)}$, can cause the production and release of the proinflammatory cytokines such as CRP, mRNA and protein expression of tumor necrosis factor alpha $(\mathrm{TNF} \alpha)$ and interleukin ${ }^{(17)}$. Systemic effect of this inflammatory process is a basic hypothesis of the association between $H$. pylori infection and extragastrointestinal (GI) diseases ${ }^{(15)}$. The inflammatory cytokines especially CRP are independent risk factor for CVD, so that it is known that inflammatory cytokines can induce function and structural vessel abnormalities in the arterial wall, by many mechanisms, such as changes in the serum lipid levels, and metabolism and production of oxidative stress. Endothelial dysfunction plays a key role in the pathogenesis of atherosclerosis, that refers to the lack of ability in endothelium to providing vascular homeostasis ${ }^{(4)}$. The endothelial dysfunction is a consequence of overproduction of vasoconstrictors and dysregulation of hemostasis, inflammation and thrombosis in endothelium of vascular wall ${ }^{(20)}$. Activation of vascular endothelium causes an upregulation of different markers including soluble vascular cell adhesion molecule-1 (sVCAM-1) and intercellular adhesion molecule 1( ICAM-1) that have direct relationship with the severity of

Declared conflict of interest of all authors: none

Funding/Support: Ilam University of Medical Sciences, Ilam, Iran, supported this study.

${ }^{1}$ Department of Gastroenterology, Ilam University of Medical Sciences, Ilam, Iran; ${ }^{2}$ Department of Cardiology, Faculty of Medicine, Ilam University of Medical Sciences, Ilam, Iran; ${ }^{3}$ Department of Pathology, Faculty of Medicine, Ilam University of Medical Sciences, Ilam, Iran; ${ }^{4}$ Department of Social Medicine, Faculty of Medicine, Ilam University of Medical Sciences, Ilam, IR Iran;

${ }^{5}$ General physician, Faculty of Medicine, Ilam University of Medical Sciences, Ilam, Iran.

Correspondence: Asghar Rahmani. Student Research Committee, Faculty of Medicine, Ilam University of Medical Sciences, Ilam, Iran. Email: asrahmani1991@yahoo.com 
atherosclerosis $^{(16)}$. In addition to these markers, some non-invasive procedures such as flow mediated dilation (FMD) and carotid intima media thickness (CIMT) can be indicators of atherosclerosis ${ }^{(19)}$. As mentioned previously, inflammation is a common feature of Helicobacter pylori and atherosclerosis ${ }^{(15)}$; however, in reality there is no study to indicate the atherogenic mechanisms of $H$. pylori and evidences are available only based on epidemiological studies. Therefore, this study aimed to investigate the relationship between $H$. pylori infection and serologic markers related to $H$. pylori with blood markers of endothelial dysfunction such as ICAM-1 and VCAM-1 and markers related to atherosclerosis such as CIMT and FMD in patients with chronic gastritis associated with H. pylori infection.

\section{METHODS}

\section{Study protocol}

This case-control study was performed among 120 participants who showed some gastrointestinal manifestations such as dyspepsia and attended to the gastroenterology clinics, for routine checks or endoscopy, in Ilam city, West of Iran, during May and November 2015. For all of participants, a detailed history including the starting time of signs and symptoms, duration of disease, past medical history and predisposing factors such as smoking, alcoholism, medication used especially Nonsteroid Anti-inflammatory Drugs (NSAID) was obtained. Patients with chronic diseases such as cardiovascular, endocrine, hematologic and respiratory disorders, pregnancy or lactation and hormone replacement therapy (HRT), antibiotic use in the previous 6 weeks, previous attempts at $H$. pylori eradication, previous gastric surgery or a previous history of alcohol consumption or drug abuse were excluded from the study. For better comparison of the results, the control group was selected among subjects who had no history of atherosclerotic risk factors or confirmed diseases. Also, controls did not show any dyspepsia symptom, or did not report a history of antibiotics, bismuth, proton pump inhibitors or NSAID application during the past 8 weeks. The Ethics Committee of Ilam University of Medical Sciences confirmed the study, and a written informed consent was obtained from each participant. All clinical procedures were performed according to the principles expressed in the Helsinki declaration.

\section{Detection of $\boldsymbol{H}$. pylori infection}

H. pylori infection was detected via cultivation of two biopsy samples taken from antrum of stomach in a transport medium (Portagerm pylori, bioMe'rieux, Marc l'Etoile, France) and Urease Breath Test (UBT) viaa CLOtest (Tri-Med Specialities, Osborne Park, Western Australia). In addition, two biopsy samples were taken from antrum and corpus of stomach for histopathologic assessment. Three different tests including UBT, histology and cultivation of $H$. pylori were performed for confirmation of infection and if the results of all tests were positive, the patient was considered as an infected individual for $H$. pylori.

\section{Endoscopic evaluations}

All participants were inspected by the same upper Olympus (GIF-V) endoscopic apparatus. Endoscopy was performed by a gastrointestinal subspecialist and the biopsy needle as well as the apparatus were sterilized for each patient separately. All patients were sedated by $10 \%$ oral xylocaine spray and $5.5-7 \mathrm{mg}$ midazolam intravenously and samples of biopsies were taken by the same needle and the same method. Endoscopy was done at a lying position on the left side and after macroscopic evaluations, the needed biopsy samples were taken from the different parts of the stomach.

\section{Histology}

In this study, histological assessment was performed according to the Sydney System for the classification of gastritis. Hematoxylin-Eosin (H\&E) staining was preformed for the $H$. pylori diagnosis and histological findings. For confirming the presence of H. pylori "Giemsa" stain was also done. Identification of rods and curved gram-negative organisms in the mucosal surface in the pit of stomach with $\times 40$ zoom of light microscope was precisely sought by expert individuals. The existence of at least five bacilli per microscopic field was necessary for confirmation. Infiltration of lymphocytes and plasma cells in the lamina propria were considered as signs of chronic gastritis and neutrophil infiltration was considered as sign of active gastritis. The presence of goblet cells and replacement of mucosal cylindrical cells by absorption cells was considered as a sign of intestinal metaplasia ${ }^{(17)}$.

\section{FMD assay}

FMD measurement was preformed by ultrasound imaging with 18-MHz linear array transducer on M-mode (Acuson S3000; Siemens). All measurements were performed at the morning and all patients had 30 minutes rest and were inhibited to consume coffee or a special diet.

\section{Carotid intima media thickness assay}

CIMT assessment was performed for all participants using B-mode ultrasonography (Esaote, MylabTM 70 Co., Italy) using a high-resolution, 18-MHz linear array transducer. All measurements were performed by a radiologist who was blinded to the clinical conditions of patients. According to a previous study, the CIMT of both left and right common carotid arteries was measured only once, and the CIMT value was calculated by averaging the measurements of left and right common carotid IMT.

\section{Laboratory assay}

After a fasting of 12 hours, $10 \mathrm{~mL}$ of blood sample from brachial vein was collected from all participants. Samples were centrifuged for 5 minutes at $4000 \mathrm{rpm}$ and then were frozen and stored at $-70^{\circ} \mathrm{C}$ until the time of assessment. sICAM-1 and sVCAM-1 levels were measured with sandwich enzyme immunoassay technique (Elisa) kits (Bender medical systems GmbH Viena, Austria).

\section{Statistical analysis}

Data analysis was performed by SPSS 19) SPSS Inc, Chicago, USA) software. The results were expressed as mean \pm SD for quantitative variables and or frequencies for qualitative variables. The normality of data was assessed by Kolmogorov-Smirnov test. The Student's $t$-test and the chi-square test were applied for comparison of the results. A level of equal or less than 0.05 was considered statistically significant for all variables. 


\section{RESULTS}

\section{Basic information of subjects}

Basic and clinical findings of subjects are showed in Table 1. In the control group, $21(52.5 \%)$ participants were male and 19 (47.5) were female. In the $H$. pylori positive group, $18(45 \%)$ patients were male and $22(55 \%)$ were female. Twenty three $(57.5 \%)$ patients of the $H$. pylori negative group were male and $17(42.5 \%)$ were female. There wasn't any significant difference between three studied groups for gender $(P=0.876)$. Mean \pm standard deviation (SD) for age among control, negative and positive $H$. pylori groups were $47.21 \pm 7.54,46.52 \pm 5.52$ and $45.64 \pm 8.32$ years respectively $(P=0.943)$. Five $(12.5 \%)$ participants in the control group, six $(15 \%)$ patients in the positive and seven $(17.5 \%)$ patients in the negative $H$. pylori groups reported alcohol consumption $(P=0.245)$. Also, four $(10 \%)$ participants in the control group were current smokers and $10(25 \%)$ others were passive smokers. In the positive $H$. pylori group, six $(15 \%)$ patients and $12(30 \%)$ patients and in the negative $H$. pylori group $8(20 \%)$ patients and $9(22.5 \%)$ patients were current and passive smokers respectively $(P=0.032)$. NSAID was applied by 12 participants in the control group, $16(40 \%)$ patients in the positive $H$. pylori and $14(35 \%)$ patients in the negative $H$. pylori groups respectively $(P=0.042)$. The frequencies of atrophy, metaplasia and dysplasia among the positive $H$. pylori group were $12(30 \%), 10(25 \%)$ and 14 $(35 \%)$ respectively and among the negative $H$. pylori group these figures were $15(37.5 \%), 7(17.5 \%)$ and $13(32.55 \%)$ respectively. Mean \pm SD of IgG in the positive and negative $H$. pylori groups were $87.54 \pm 12.32 \mathrm{IU} / \mathrm{mL}$ and $14.32 \pm 6.43 \mathrm{IU} / \mathrm{mL}$ respectively with a high significant difference $(P=0.000)$.

\section{Relationship between endothelial dysfunction and H. pylori}

The level of endothelial dysfunction among both negative and positive $H$. pylori groups is showed in Table 2 . Mean \pm SD of FMD in the control group $(0.27 \% \pm 0.11)$ was significantly higher in comparison with the positive $(0.17 \% \pm 0.09, P=0.034)$ and negative $H$. pylori groups $(0.21 \% \pm 0.10, P=0.041)$. Also, the mean $\pm \mathrm{SD}$ of CIMT in the positive $H$. pylori group $(0.58 \pm 0.13 \mathrm{~mm})$ was significantly higher than that in the control $(0.36 \pm 0.44 \mathrm{~mm}$, $P=0.021)$ and negative $H$. pylori groups $(0.48 \pm 0.32 \mathrm{~mm}, P=0.040)$. Mean \pm SD of CIMT in the chronic gastritis patients with negative $H$. pylori was significantly higher than that for participants in the control group $(P=0.037)$. Mean \pm SD of sICAM-1 in the chronic gastritis patients with positive and negative $H$. pylori was significantly higher than that for participants in the control group (332.64 $\pm 8.75 \mathrm{pg} / \mathrm{mL}, 352.16 \pm 7.54 \mathrm{pg} / \mathrm{mL}, 236.32 \pm 12.43 \mathrm{pg} / \mathrm{mL}$, $P=0.000$, respectively). Level of sICAM-1 in positive $H$. pylori group was higher than that in the negative $H$. pylori group but this difference was not significant $(P=0.053)$. Mean $\pm \mathrm{SD}$ of $\mathrm{sV}$ CAM-1 in patients with positive $H$. pylori $(731.43 \pm 21.34 \mathrm{pg} / \mathrm{mL})$ was significantly higher than that in the negative $H$. pylori patients $(665.45 \pm 17.54 \mathrm{pg} / \mathrm{mL}, P=0.001)$ as well as those in the control group (456.54 $\pm 24.32, P=0.000)$. Also the level of sVCAM-1 in the negative $H$. pylori group was significantly higher than that in the control group $(P=0.000)$.

TABLE 1 . Basic characteristics of participants

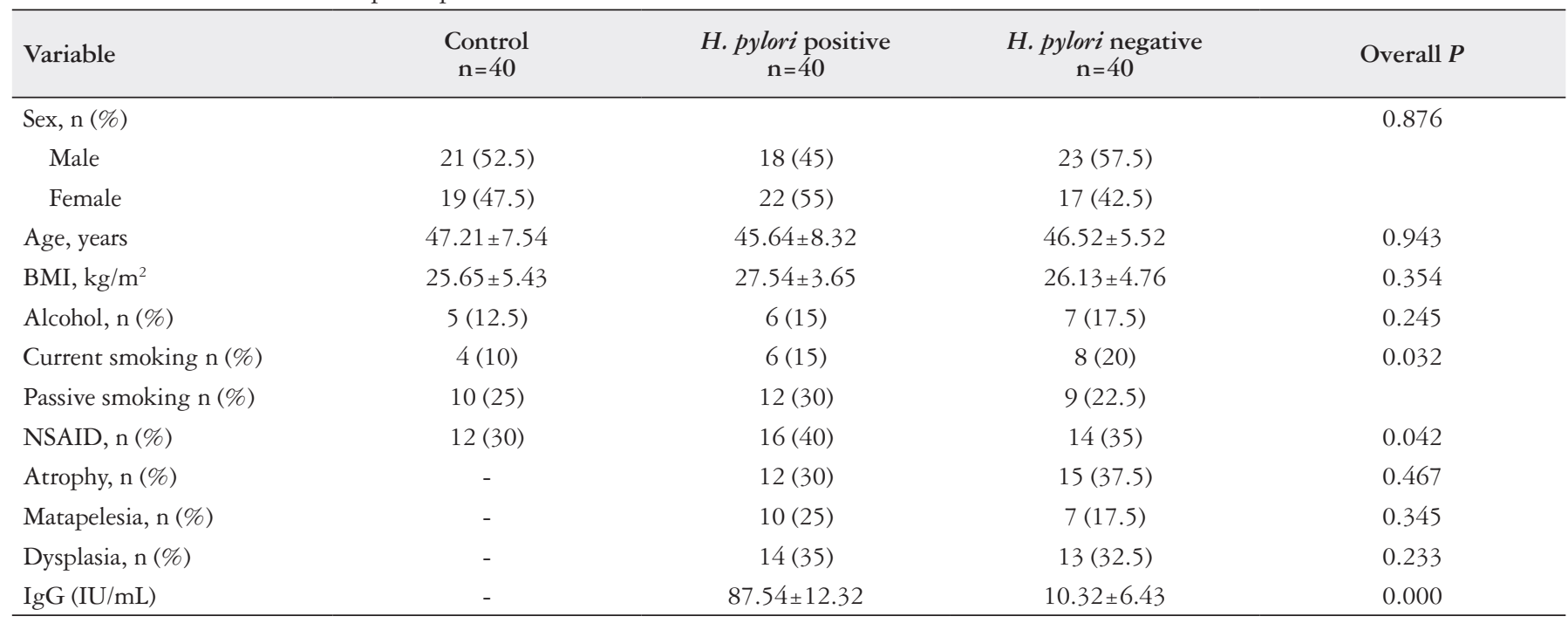

BMI: body mass index; NSAID: nonsteroid anti-inflmmatory drugs.

TABLE 2. Compression the level of endothelial dysfunction markers in patients with chronic gastritis associated with $H$. pylroi infection

\begin{tabular}{lccc}
\hline Variable & Control & H. pylori positive & H. pylori negative \\
\hline FMD, $\%$ & $0.27 \pm 0.11$ & $0.17 \pm 0.09^{\mathrm{a}}$ & $0.21 \pm 0.10^{\mathrm{a}, \mathrm{b}}$ \\
CIMT, mm & $0.36 \pm 0.44$ & $0.58 \pm 0.13^{\mathrm{a}}$ & $0.48 \pm 0.32^{\mathrm{a}, \mathrm{b}}$ \\
sICAM-1 $(\mathrm{pg} / \mathrm{mL})$ & $236.32 \pm 12.43$ & $352.16 \pm 7.54^{\mathrm{a}}$ & $332.64 \pm 8.75^{\mathrm{a}}$ \\
sVCAM-1 $(\mathrm{pg} / \mathrm{mL})$ & $456.54 \pm 24.32$ & $731.43 \pm 21.34^{\mathrm{a}}$ & $665.45 \pm 17.54^{\mathrm{a}, \mathrm{b}}$ \\
\hline
\end{tabular}

FMD: flow mediated dilation; CIMT: carotid intima media thickness; Sicam-1: soluble inter cellular adhesion molecule-1; Svcam-1: soluble vascular cell adhesion molecule; a: $P=<0.05$ compared to control group; b: $P<0.05$ compared to $H$. pylori positive. 


\section{Relationship between IgG level with markers of endothelial dysfunction}

Figure 1 shows the correlation between markers of endothelial dysfunction and the level of $\operatorname{IgG}$ as the serological marker of $H$. pylori infection. Based on the results, the level of IgG had a revers correlation with FMD, so that by increasing the serum level of $\mathrm{IgG}$, the level of FMD was reduced, but this correlation was not significant $(P=0.247)$. Regardless to FMD, the level of CIMIT increased with increasing the serum level of $\operatorname{IgG}(P=0.563)$.

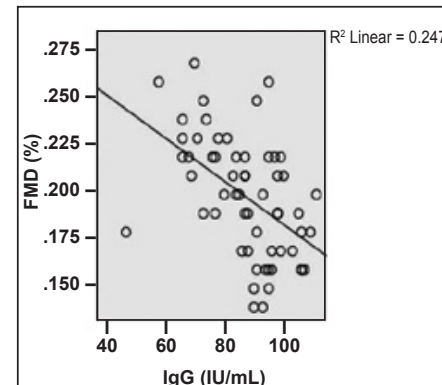

A

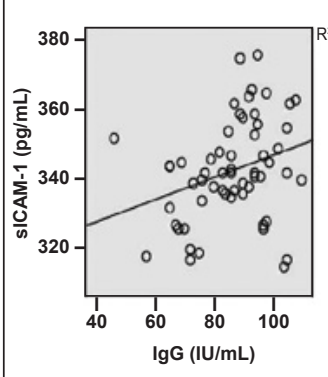

C

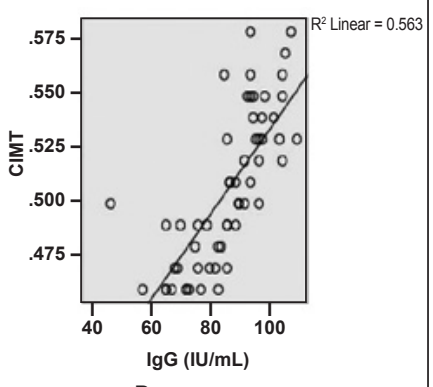

B

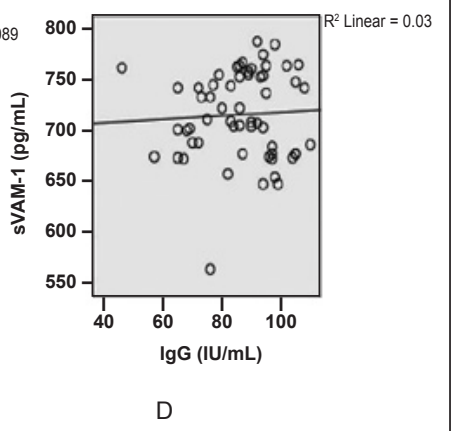

FIGURE 1. Association between endothelial dysfunction markers and $H$. pylori IgG in patients with chronics gastritis associated with $H$. pylori infection. FMD: flow mediated dilation; CIMT: carotid intima media; sICAM: soluble inter cellular adhesion molucle-1; sVCAM: soluble vascular cell adhesion molucle; FMD: flow mediated dilation, CIMT: carotid intima media; sICAM: soluble intera cellular adhesion molucle-1; sVCAM: soluble vascular cell adhesion molucle.

\section{DISCUSSION}

The aim of this study was to assess the endothelial dysfunction in patients with chronic gastritis associated with $H$. pylori infection. Some blood markers such as sICAM-1 and sVCAM-1 as well as some vascular markers such as FMD and CIMT were measured in this study. Endothelial dysfunction is a key component of maintaining structure and vascular function through various mechanisms ${ }^{(9)}$. According to the results, changes of FMD in patients with positive $H$. pylori infection showed significant differences with FMD changes in healthy subjects as well as those with negative $H$. pylori infection. Although many studies have reported a relationship between $H$. pylori infection and coronary artery diseases and also vascular events such as atherosclerosis, but these studies were cross sectional or epidemiological reports ${ }^{(5)}$ and there is not a specific study to investigate the effects mechanism of $H$. pylori infection on vascular changes. This study showed the relationship between $H$. pylori infection and FMD changes and endothelial dysfunction during chronic gastritis disease for the first time. Another interesting finding in results was the FMD changes in patients with $H$. pylori infection was significantly lower than those in patients without $H$. pylori infection. Also, early changes in the endothelial dysfunction were higher among chronic gastric patients compared to healthy controls, but these changes in the patients with chronic gastritis associated with $H$. pylori infection were higher than those in the chronic gastritis without $H$. pylori infection and healthy people. Due to lack of similar studies, we could not compare the results of this study with other findings. Blum and colleagues reported that $H$. pylori eradication could improve endothelial dysfunction according to attenuated FMD and ankle brachial index after 3 months ${ }^{(3)}$. This study also revealed a reverse correlation between FMD changes and the serum level of $\mathrm{IgG}$ as a serological marker of $H$. pylori infection, for the first time. In a study by Ozdogru and colleagues, the relationship between IgG titer and the extent of coronary artery disease was reported among patients with angiography proven coronary artery disease (CAD) as well as those with acute coronary syndrome (ACS) $)^{(14)}$, while Hara and colleagues have rejected this kind of association ${ }^{(6)}$. This study showed a direct association between CIMT and IgG titer in chronic gastritis associated with $H$. pylori infection compared to the healthy subjects and furthermore compared to patients with negative $H$. pylori infection. CIMT is an indicator of structural changes in vascular wall and measuring this marker can predict future risk of cardiovascular events ${ }^{(13)}$. Fortunately, some studies have limitedly investigated the association between CIMT and H. pylori infection ${ }^{(10)}$. For example, Akbas and colleagues reported that the CIMT among positive $H$. pylori subjects was significantly higher than that in those with negative $H$. pylori infection ${ }^{(1)}$. Findings of this study were in accordance with the results of Akbas et al. Of course, our study was relatively different from Akbas study, so this study compared chronic gastric patients either with or without H. pylori infection with the healthy subjects. Nevertheless, Altintas and colleagues reported that carotid intima-media thickness was higher among positive $H$. pylori patients with atrophic gastritis compared to positive $H$. pylori patients with non-atrophic gastritis but their difference was not significant ${ }^{(2)}$. In addition, we have shown a direct linear correlation between the CIMT rate and the serum level of $\mathrm{IgG}$ that this finding has not been reported so far. Another important aspect of this study was assessment of blood markers associated with endothelial dysfunction such as sICAM-1 and sVCAM-1 in patients with chronic gastritis associated with H. pylori infection. We showed that the levels of sICAM-1 and sVCAM-1 in chronic gastritis patients associated with $H$. pylori infection were significantly higher compared to those without $H$. pylori infection. In addition, the level of these two markers in chronic gastritis patients with or without $H$. pylori infection was significantly higher in comparison with healthy individuals. According to Mori's study, H. pylori infection, directly, induced expression of ICAM-1 during culturing of gastric epithelial cells in a NF-kappa B-dependent manner ${ }^{(11)}$. In another study, findings showed a significant role of ICAM-1 and VCAM-1 in leukocyteendothelial interaction among patients with chronic gastritis associated $H$. pylori infection without E-selectin upregulation ${ }^{(7)}$. This finding was in accordance with our results. We showed that a direct association between serum level of $\mathrm{IgG}$ and increasing level of ICAM-1 and VCAM-1 in chronic gastritis patients. This result was not reported so far and this issue was performed by this study for the first time. As it was previously mentioned, there 
are few studies to show the changes in the endothelial dysfunction markers among chronic gastritis patients and we showed a completely elaborated endothelial dysfunction in patients with chronic gastritis. We showed that these dysfunctions were exacerbated in the presence of $H$. pylori infection. One of the limitations of our study was a small sample size of participants, mostly due to narrow criteria in the selection of patients for inclusion. Considering the role of $H$. pylori in the endothelial dysfunction, if the effects of Helicobacter pylori eradication on improving of endothelial function to be evaluated by the clinical trials studies, better results could be expected about the pathogenesis of this disease. In addition, new therapeutic strategies for endothelial dysfunction in chronic gastritis disease associated with $H$. pylori infection may be achieved.

\section{ACKNOWLEDGEMENTS}

We thank colleagues in the Faculty of Medicine, Ilam University of Medical Sciences, participants, coordinators and data reviewers who assisted in this study.

\section{Authors' contributions}

Judaki A and Rahmani A contributed to data analysis, interpretation of the results and drafted the manuscript. Rahmani A participated in manuscript preparation. Hafezi Ahmadi MR, Mis Ghavam S and Asadollahi KH participated in data collection. Norozi S contributed to the design of the study and participated in the clinical work and manuscript preparation. All authors have read and approved the article for publication.

Judaki A, Norozi S, Ahmadi MRH, Ghavam SM, Asadollahi K, Rahmani A. Fluxo mediado pela dilatação e espessura da íntima-média da carótida em pacientes com gastrite crônica associada com infecção por Helicobacter pylori. Arq Gastroenterol. 2017;54(4):300-4.

RESUMO - Contexto - A disfunção endotelial é um dos estágios iniciais de doenças vasculares. Objetivo - O objetivo deste estudo foi investigar os marcadores de disfunção endotelial em pacientes com gastrite crônica associada com infecção por Helicobacter pylori (H. pylori). Métodos - Através de estudo cruzado seccional, foram analisadas informações básicas e clínicas de 120 participantes (40 pacientes com infecção pelo $H$. pylori, 40 pacientes sem infecção pelo H. pylori e 40 pessoas saudáveis). A espessura da camada íntima-média da carótida e níveis de dilatação mediada por fluxo foram medidos em todos os pacientes e controles. A adesão da molécula-1 solúvel (sVCAM-1) à célula vascular e da molécula de adesão intercelular-1 (ICAM-1) foram medidas pelo método Elisa para todas os indivíduos. O nível de $H$. pylori IgG foi avaliado em pacientes de gastrite crônica. Resultados - O nível de dilatação mediada por fluxo em pacientes com infecção positiva pelo $H$. pylori foi significativamente menor do que em aqueles com infecção negativa $(0,17 \% \pm 0,09) \times(0,21 \% \pm 0,10) P<0,05$ e em relação ao grupo controle $(0,27 \% \pm 0,11) P<0,05)$. O nível da espessura da íntima-média da carótida em pacientes com infecção positiva pelo $H$. pylori foi significativamente maior $(0,58 \pm 0,13 \mathrm{~mm})$ do que aqueles com negativa $(0,48 \pm 0,32 \mathrm{~mm})$ $P<0,05)$ e em relação ao grupo controle $(0,36 \pm 0,44 \mathrm{~mm}) P<0,05)$. O nível médio de sICAM-1 grupo de infecção H. pylori positiva $(352,16 \pm 7,54$ pg/ $\mathrm{mL})$ foi maior do que o grupo de infecção negativa $(332,64 \pm 8,75 \mathrm{pg} / \mathrm{mL}=0,75)$ e em relação ao grupo controle $(236,32 \pm 12,43 \mathrm{pg} / \mathrm{mL}) P<0,05)$. Revelou-se uma relação direta entre a dilatação mediada por fluxo e alterações da espessura da íntima-média da carótida e sICAM-1 e sVCAM-1, associada com o nível de H. pylori IgG em gastrite crônica. Conclusão - Os níveis de dilatação mediada por fluxo, da espessura da íntima-média da carótida e sICAM-1 foram maiores entre os pacientes com infecção positiva pelo H. pylori. Pacientes com gastrite crônica associada a infecção por H. pylori correm o risco de disfunção endotelial, devido à dilatação mediada por fluxo e anormalidades da espessura da íntima-média da carótida e aumento do nível de sICAM-1 e sVCAM-1.

DESCRITORES - Gastrite. Helicobacter pylori. Fatores de crescimento endotelial. Espessura intima-media carotídea.

\section{REFERENCES}

1. Akbas HS, Basyigit S, Suleymanlar I, Kemaloglu D, Koc S, Davran F, Demir I, Suleymanlar G.The assessment of carotid intima media thickness and serum paraoxonase-1 activity in Helicobacter pylori positive subjects. Lipids Health Dis. 2010;30:92.

2. Altintas E, Ucbilek E, Ulu O, Sezgin O, Uzer C, Tataroglu C, Camdeviren H. Helicobacter pylori-associated atrophic gastritis and carotid intima-media thickness: is there a link? Int J Clin Pract. 2007;61:810-4.

3. Blum A, Tamir S, Mualem K, Ben-Shushan RS, Keinan-Boker L, Paritsky M. Endothelial dysfunction is reversible in Helicobacter pylori-positive subjects. Am J Med. 2011;124:1171-4

4. Gimbrone MA Jr, García-Cardeña G. Endothelial Cell Dysfunction and the Pathobiology of Atherosclerosis. Circ Res. 2016;118:620-36.

5. Haider AW, Wilson PW, Larson MG, Evans JC, Michelson EL, Wolf PA, O'Donnell CJ, Levy D. The association of seropositivity to Helicobacter pylori, Chlamydia pneumoniae and cytomegalovirus with risk of cardiovascular disease: a prospective study. J Am Coll Cardiol. 2002;40:1408-13.

6. Hara K, Morita Y, Kamihata H, Iwasaka T, Takahashi H. Evidence for infection with Helicobacter pylori in patients with acute myocardial infarction. Clin Chim Acta. 2001;313:87-94

7. Hatz RA, Rieder G, Stolte M, Bayerdörffer E, Meimarakis G, Schildberg FW, Enders G.Pattern of adhesion molecule expression on vascular endothelium in Helicobacter pylori-associated antralgastritis. Gastroenterology. 1997;112:1908-19.

8. $\mathrm{Hu}$ Y, Liu JP, Zhu Y, Lu NH. The Importance of Toll-like Receptors in NF-кB Signaling Pathway Activation by Helicobacter pylori Infection and the Regulator of this Response. Helicobacter. 2016;13(6).

9. Luscher TF, Barton M. Biology of the endothelium. Clin Cardiol. 1997;20:3-10.

10. Markus H, Kapozsta Z, Ditrich R, Wolfe C, Ali N, Powell J, Mendell M, Cullinane $\mathrm{M}$. Increased common carotid intima-media thickness in UK African Caribbeans and its relation to chronic inflammation and vascular candidate gene polymorphisms. Stroke. 2001;32:2465-71
11. Mori N, Wada A, Hirayama T, Parks TP, Stratowa C, Yamamoto N. Activation of intercellular adhesion molecule 1 expression by Helicobacter pylori is regulated by NF-kappa B in gastric epithelial cancer cells. Infect Immun. 2000;68 1806-14

12. Muhlestein JB, Anderson JL. Chronic infection and coronary artery disease. Cardio Clin. 2003;21:333-62.

13. O 'Leary DH, Polak JF, Kronmal RA, et al. Carotid-artery intima and media thickness as a risk factor for myocardial infarction and stroke in older adults. Cardiovascular Health Study Collaborative Research Group. N Engl J Med. 1999;340:14-22.

14. Ozdogru I, Kalay N, Dogan A. Inanc MT, Kaya MG, Topsakal R, Gul I, Kutukoglu I, Kilic H, Eryol NK. The relationship between Helicobacter pylori IgG titre and coronary atherosclerosis. Acta Cardiol. 2007;62:501-5.

15. Pellicano R. Helicobacter pylori and cardiovascular disease: any missing data? Eur Rev Med Pharmacol Sci. 2015;19:4684-5.

16. Prasad M, McBane R, Reriani M, Lerman LO, Lerman A. Coronary endothelia dysfunction is associated with increased risk of venous thromboembolism. Thromb Res. 2016;139:17-21.

17. Rahmani A, Moradkhani A, Hafezi Ahmadi MR, Jafari Heirdarlo A, Abangah $\mathrm{G}$ and et al. Association between serum levels of high sensitive $\mathrm{C}$-reactive protein and inflammation activity in chronic gastritis patients. Scand J Gastroenterol. 2016;51:531-7.

18. Tan HJ, Goh KL. Extragastrointestinal manifestations of Helicobacter pylori infec tion: facts or myth? A critical review. J Dig Dis. 2012;13:342-9.

19. Taslipinar A, Yaman H, Yilmaz MI, Demirbas S, Saglam M, Taslipi-nar MY, et al The relationship between inflammation, endothelial dysfunction and proteinuria in patients with diabetic nephropa-thy. Scand J Clin Lab Invest. 2011;71:606-12.

20. Vita JA, Keaney JF Jr. Endothelial function: a barometer for car- diovascular risk? Circulation. 2002;106:640-2. 